ORIGINAL ARTICLE

\title{
Effectiveness of Ponseti Versus Kite Method for the Management of Club Foot- A Quasi Experimental Trial
}

\author{
SHABANA SHARIF ${ }^{1}$, REHAN RAMZAN KHAN², SAIMA RIAZ ${ }^{3}$, SAJID RASHID ${ }^{4}$, ZAIGHAM RASOOL ATHAR ${ }^{5}$, TAUSIF \\ AAMIR $^{6}$, MOHAMMAD MOHSIN KHAN ${ }^{7}$ \\ ${ }^{1}$ Physiotherapist Internee, District Head Quarter Hospital, Layyah, Pakistan. \\ ${ }^{2}$ Assistant Professor, Multan College of Physiotherapy, Multan Medical \& Dental College, Multan, Pakistan. \\ ${ }^{3}$ Assistant Professor, Riphah College of Rehabilitation and Allied Health Sciences, Riphah International University, Lahore, Pakistan. \\ ${ }^{4}$ Professor, Multan College of Physiotherapy, Multan Medical \& Dental College, Multan, Pakistan. \\ ${ }^{5}$ Senior Physiotherapist, Sindh Institute of Physical Medicine and Rehabilitation, Karachi, Pakistan. \\ ${ }^{6}$ Physiotherapist, Shifa International Hospital, Islamabad, Pakistan. \\ ${ }^{7}$ Professor Community Medicine NM\&DC \\ Correspondence to: Dr. Rehan Ramzan Khan, MS-OMPT, Email: rehan99physio@gmail.com, Cell:03343074756
}

\begin{abstract}
Objective: To determine the effectiveness of ponseti versus kite method for the management of club foot among children.

Methods: A quasi experimental trial was conducted to determine the most effective conservative method for managing idiopathic club foot. This study was carried out in District Head Quarter Hospital, Layyah. A total of 46 children (60 Feet) aged less than six months of both genders were included in this study using convenience sampling technique. The study sample was divided into Group A (Ponseti) and Group B (Kite). Each treatment group comprises of 30 feet. Patients were called for weekly follow up till ten weeks consecutively. At every followup visit, patients were assessed to check the improvement of deformity with the help of the Pirani scoring system for the foot. Pirani score difference was measured in both treatment groups from the baseline until the last followup interval until the $10^{\text {th }}$ Week. Pirani score difference was measured in both treatment groups from the baseline until the last follow-up interval until the $10^{\text {th }}$ Week. A greater negative value signified better correction. SPSS 23 was used for data entry and analysis.

Results: Children's mean age in both treatment groups (A and B) was $10.83 \pm 4.59$ and $10.20 \pm 4.75$ weeks. At presentation mean Pirani score in both treatment groups (A and $B$ ) was $5.85 \pm 0.67$ and $5.86 \pm 0.45$, respectively, while at $10^{\text {th }}$ follow up it was $1.42 \pm 0.39$ and $2.35 \pm 0.54$ for group $A$ and group $B$, respectively.

Conclusion: This study demonstrates that the Ponseti technique significantly improved the management of club foot as that of the Kites method. Ponseti's method is more effective in terms of rapid improvement in the involved group.

Key words: Non operative Management, Idiopathic Club foot, Kites method, Ponseti method.
\end{abstract}

\section{INTRODUCTION}

Clubfoot, also known as talipes equinovarus (TEV), is a musculoskeletal birth abnormality that affects 1 to 5 out of every thousand surviving neonates (1). In nearly half of the instances, the involvement is bilateral, and in unilateral cases, the right side is more usually afflicted than the left. Males are more likely than females to develop idiopathic clubfoot, with a ratio of $2: 1$. (2) and (3) It depicts a fourcomponent congenital foot deformity: forefoot adduction, ankle equinus, midfoot cavus, and hindfoot varus $(2,4)$. Most TEV presents as separate deformities without any known reason, while around $20 \%$ of TEV are related to neuromuscular and hereditary issues. Without appropriate treatment, the deformed feet may lead to disability in walking and running (5). Two well-known sequential casting methods were presented in last century. One of the pioneers that portrayed the non-surgical method of foot deformity correction was J. H. Kite (6). Kite strategy intends to accomplish the gradual correction of each deformity in a specific sequence. This sequence begins with amending the forefoot adduction, then inversion deformity of the hind foot varus is corrected, and lastly, the ankle equinus is corrected. The correction of next deformity is done only when the previous deformity is corrected completely (7). Then, at that point, Ignacio Ponseti fostered his manipulative and casting strategy to correct the deformity from 1940 to 1950. Ponseti's correction maneuver adjusts the deformations, including midfoot cavus, forefoot adduction, and hind foot varus, aside from the equinus deformity (4). Clubfoot is an easily recognizable deformity. When left untreated, children having strolls on the sides and top of their feet prompts callus development, skin and bone contaminations, many mobility restrictions, and failure to wear normal footwear. The disfigurement in the idiopathic club foot has both cosmetic and functional consequences $(7,8)$.

Ponseti professes to avoid open surgery in $89 \%$ of cases utilizing his method of casting and manipulation. Cooper and Dietz analyzed Ponseti's cases with an average of 30 years of follow-up and tracked down that $78 \%$ of the patients had accomplished superb functional and clinical results compared with $85 \%$ in a control group without intrinsic foot disfigurement (9).

Of the two casting strategies, i.e. Ponseti and Kite, which strategy can give an enduring and better result is still under debate. Hence, we chose to conduct a trial to think about the result of idiopathic clubfoot by using Ponseti and Kite method.

\section{METHODS}

A quasi-experimental trial was conducted to find out the most influential conservative method for managing 
idiopathic club foot. After taking ethical permission from the ethical review committee, this study was carried out in District Head Quarter Hospital, Layyah. A total of 46 children (60 Feet) aged less than six months of both genders were included in this study using the convenience sampling technique. The study sample was divided into Group A (Ponseti) and Group B (Kite). Each treatment group comprises 30 feet. Patients were called for weekly follow up till ten weeks consecutively. At every follow-up visit, patients were assessed to check the improvement of deformity with the help of the Pirani scoring system for the foot. Pirani score difference was measured in both treatment groups from the baseline until the last follow-up interval until the $10^{\text {th }}$ Week. A greater negative value signified greater correction. Patients were assessed as per a standardized questionnaire and the severity of TEV was noted by using the Pirani clubfoot score. SPSS 23 was used for data entry and analysis. Quantitative variables were presented with the help of mean and standard deviation, while qualitative variables were presented as frequency and percentages. Repeated measure ANOVA was applied to see the overall and group-wise reduction in Pirani score during the follow-up time. P-value $\leq 0.05$ was taken as significant.

\section{RESULTS}

The demographic characteristics of the participants of both groups is presented in table-I. The mean age of children in both treatment groups (A and B) was 10.83 \pm 4.59 and $10.20 \pm 4.75$ weeks.

Table-I: Demographics of Participants from Both Groups

\begin{tabular}{|l|l|l|}
\hline & Group A (Ponseti) & Group B (Kite) \\
\hline Age (weeks) & $10.83 \pm 4.59$ & $10.20 \pm 4.75$ \\
\hline Gender & & \\
\hline Male & $12(54 \%)$ & $13(55 \%)$ \\
\hline Female & $10(46 \%)$ & $11(45 \%)$ \\
\hline Laterality & & \\
\hline Right & $11(36.7 \%)$ & $7(23.3 \%)$ \\
\hline Left & $3(10 \%)$ & $11(36.7 \%)$ \\
\hline Bilateral & $8(26.7 \%)$ & $6(20 \%)$ \\
\hline
\end{tabular}

Table-II: Descriptive Statistics for Pirani score for Ponseti Method \& Kite Method

\begin{tabular}{|c|c|c|c|c|c|}
\hline & \multicolumn{4}{|c|}{ Serial Casting } & \multirow{4}{*}{$\begin{array}{l}\text { p-value } \\
\text { (Across } \\
\text { Group) }\end{array}$} \\
\hline & \multicolumn{2}{|c|}{ Group-A } & \multicolumn{2}{|c|}{ Group-B } & \\
\hline & \multicolumn{2}{|c|}{ Ponseti Method } & \multicolumn{2}{|c|}{ Kite Method } & \\
\hline & \multicolumn{2}{|c|}{ Mean \pm SD } & \multicolumn{2}{|c|}{ Mean \pm SD } & \\
\hline Baseline & 5.85 & 0.67 & 5.86 & 0.45 & 0.96 \\
\hline Week-1 ${ }^{\text {st }}$ & 5.01 & 0.57 & 5.05 & 0.50 & 0.76 \\
\hline Week- $2^{\text {nd }}$ & 4.54 & 0.56 & 4.70 & 0.50 & 0.24 \\
\hline Week-3 $3^{\text {rd }}$ & 4.18 & 0.56 & 4.37 & 0.50 & 0.18 \\
\hline Week-4 ${ }^{\text {th }}$ & 3.68 & 0.56 & 4.27 & 0.52 & 0.00 \\
\hline Week- $5^{\text {th }}$ & 3.19 & 0.56 & 4.02 & 0.53 & 0.00 \\
\hline Week- $6^{\text {th }}$ & 2.80 & 0.55 & 3.63 & 0.53 & 0.00 \\
\hline Week- $7^{\text {th }}$ & 2.40 & 0.53 & 3.30 & 0.53 & 0.00 \\
\hline Week- $8^{\text {th }}$ & 1.91 & 0.51 & 3.02 & 0.55 & 0.00 \\
\hline Week-9th & 1.70 & 0.50 & 2.64 & 0.54 & 0.00 \\
\hline Week- $10^{\text {th }}$ & 1.42 & 0.39 & 2.35 & 0.54 & 0.00 \\
\hline
\end{tabular}

In Group A (Ponseti), 11 children had right side affected, three children had left side affected, and 8 children with both sides were affected, while in Group B (Kite) 7 children had right side affected, 11 children had left side affected and 6 children with both sides were affected. At presentation mean Pirani score in both treatment groups (A and B) was $5.85 \pm 0.67$ and $5.86 \pm 0.45$, respectively. Descriptive Statistics of Pirani score for Ponseti and Kites Method is presented in table-II. Repeated measure ANOVA was applied to see the overall and group-wise reduction in Pirani score during the follow-up time. Results showed a decrease in Pirani score in both treatment groups, i.e. $p$ value (factor) $=0.00$. However, the decrease in the Pirani score was significantly higher in the Ponseti method group. The trend of Pirani score in both treatment groups during follow up time duration is presented in detail in figure-l

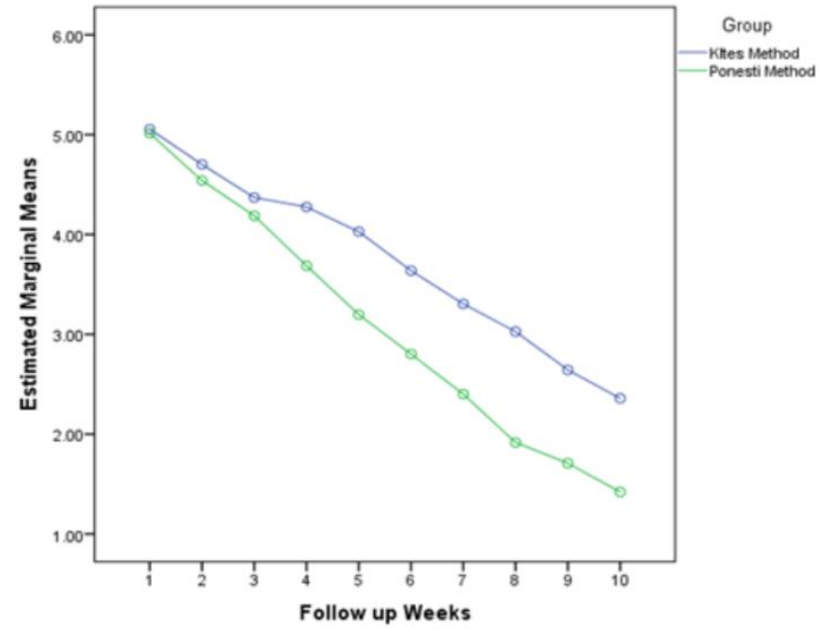

Fig-l: Trend of Pirani scores in both treatment groups during follow up time duration

\section{DISCUSSION}

Congenital talipes equinovarus, commonly known as club foot, is multifaceted abnormality of foot among children. $(10,11)$ In the past, club foot was treated by the conservative method of casting and manipulation initiated by Kite. The reported success rate was unsatisfactory. (12) In this study, we compared the Ponseti method with the Kites method for treating club feet. In both treatment groups, patients were followed up till ten weeks. Mean Pirani score was significantly higher in patients who were treated with Kites method showing less improvement from $2^{\text {nd }}$ week post-treatment till last follow up at $10^{\text {th }}$ Week.

According to the findings of a recently published meta-analysis, Ponseti's method is a safe and effective conventional treatment of clubfoot and decreases the required number of surgical interventions needed to correct the deformity. The conservative treatment is among the first choice of treatment for treating idiopathic clubfoot. (10) This finding supports this study's results as the Ponseti method of treatment was more effective than the Kites method for effective and precise treatment of club foot patients.

Rijal et al., in their randomized controlled trial, compared Kite and Ponseti method for treating club foot. He used a scoring system formulated by Pirani to assess and compare the outcome of both treatment modalities. Reduction in Pirani scores was more rapid with the use of the Ponseti method compared with Kite's technique. However, the follow-up period was only ten weeks that did 
not complete the standard Ponseti method. (13) Similar findings in this study showed that patients treated with the Ponseti method had Pirani scores reduced much faster.

Alok Sud et al. in 2008 his prospective randomized study in which he included 45 infants (67 feet) whose age was $<3$ months. Ponseti technique was more effective in terms of lower/minimal relapse rate, shorter treatment duration \& correction rate of deformity than the Kite technique. However, the mean follow-up period was only 24-27 months, a relatively short-term follow-up study. (14)

Sanghvi et al. 2009 in his study reported a similar success rate for both Kite and Ponseti treatments (79\% vs. $87 \%$ ), but the recurrence incidence and the remaining defect were somewhat lesser than other series. (15)

A recently published study from Taiwan reported that the correction rate of club foot deformity was significantly higher with the Ponseti method ( $p$-value=0.028). The patients were followed up for 72 months. The relapses rate for Kite Group and Ponseti Group was 50\% and 26.7\%, showing a significant difference. that is $p$-value $=0.036$. (16) The results of our study are consistent with this study.

\section{CONCLUSION}

This study demonstrates that the Ponseti method is significantly more effective than the kite method in terms of rapid improvement and least recurrence for the management of club foot.

\section{REFERENCES}

1. Pavone V, Bianca S, Grosso G, Pavone P, Mistretta A, Longo MR, et al. Congenital talipes equinovarus: an epidemiological study in Sicily. Acta orthopaedica. 2012;83(3):294-8.

2. Zionts LE, Jew MH, Ebramzadeh E, Sangiorgio SN. The influence of sex and laterality on clubfoot severity. Journal of Pediatric Orthopaedics. 2017;37(2):e129-e33.

3. Jeans KA, Karol LA, Erdman AL, Stevens Jr WR. Functional outcomes following treatment for clubfoot: ten-year followup. JBJS. 2018;100(23):2015-23.

4. Dobbs MB, Gurnett CA. Update on clubfoot: etiology and treatment. Clinical orthopaedics and related research. 2009;467(5):1146-53.
5. Engell V, Nielsen J, Damborg F, Kyvik KO, Thomsen K, Pedersen NW, et al. Heritability of clubfoot: a twin study. Journal of children's orthopaedics. 2014;8(1):37-41.

6. Kite J. Principles Involved in the Treatment of Congenital Club-Foot. Journal of Bone \& Joint Surgery, American Volume. 2003;85(9).

7. Chen C, Kaushal N, Scher DM, Doyle SM, Blanco JS, Dodwell ER. Clubfoot etiology: a meta-analysis and systematic review of observational and randomized trials. Journal of Pediatric Orthopaedics. 2018;38(8):e462-e9.

8. Ponseti IV, Smoley EN. The classic: congenital club foot: the results of treatment. Clinical orthopaedics and related research. 2009;467(5):1133-45.

9. Cooper DM, Dietz FR. Treatment of idiopathic clubfoot. A thirty-year follow-up note. The Journal of bone and joint surgery American volume. 1995;77(10):1477-89.

10. Balasankar G, Luximon A, Al-Jumaily A. Current conservative management and classification of club foot: $A$ review. Journal of pediatric rehabilitation medicine. 2016;9(4):257-64.

11. Besselaar AT, Sakkers RJ, Schuppers HA, Witbreuk MM, Zeegers EV, Visser JD, et al. Guideline on the diagnosis and treatment of primary idiopathic clubfoot. Acta orthopaedica. 2017;88(3):305-9.

12. Herzenberg JE, Radler C, Bor N. Ponseti versus traditional methods of casting for idiopathic clubfoot. Journal of Pediatric Orthopaedics. 2002;22(4):517-21.

13. Rijal R, Shrestha BP, Singh GK, Singh M, Nepal P, Khanal GP, Rai P. Comparison of Ponseti and Kite's method of treatment for idiopathic clubfoot. Indian journal of orthopaedics. 2010 Apr;44(2):202-7.

14. Sud A, Tiwari A, Sharma D, Kapoor S. Ponseti's vs. Kite's method in the treatment of clubfoot-a prospective randomised study. International orthopaedics. 2008;32(3):409-13.

15. Sanghvi A, Mittal V. Conservative management of idiopathic clubfoot: Kite versus Ponseti method. Journal of Orthopaedic Surgery. 2009;17(1):67-71.

16. Chen C, Wang T-M, Wu K-W, Huang S-C, Kuo KN Comparison of two methods for idiopathic clubfoot treatment: A case-controlled study in Taiwan. Journal of the Formosan Medical Association. 2019;118(2):636-40. 